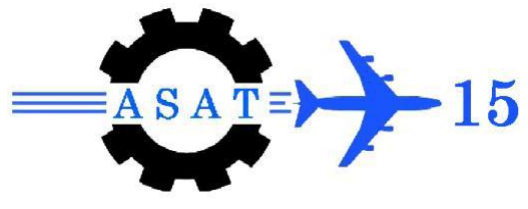

\title{
Modeling of End-Burning Solid Propellant Gas Generator
}

\author{
A. E. Makled*, W. B. El-hasumi ${ }^{\dagger}$
}

\begin{abstract}
The Solid Propellant Gas Generator (SPGG) is widely used for special military and space applications, in view of its simplicity, light weight, size and high reliability. A mathematical model that describes the burning characteristics inside the SPGG has been established and validated through the implementation of appropriate software. These two methods enabled to predict the performance and to draw the time variation of chamber pressure. An experimental work is carried out in order to prove the functionality and check the validity of the developed techniques. The comparison between the computational results and the experimental measured parameters showed a deviation error less than $4 \%$.
\end{abstract}

The presented software is considered as a powerful tool for selecting the SPGG design parameters in the stages of preliminary design and for performing further sensitivity analyses.

Keywords: Solid propellant, gas generator, internal ballistics, end burning

\section{Introduction}

The GG is used as the source of gas that results from chemical propellant combustion, solid, liquid, hybrid propellant and mono-propellant (MP) decomposition via catalytic bed. Other alternatives are the gas bleeding by sublimation of chemical solid propellant or the direct use of high pressure stored gas.

The first system powered by GG appeared during the $2^{\text {nd }}$ World War, 1944 [2]. At that time, the use of GG has greatly expanded, and today they have numerous applications in the aeronautics and space sectors, military missiles and commercial activities. The GG is usually characterized by light weight, high power and long duration energy source. The GGs are classified according to propellant type, as liquid bi-propellant LPGG, liquid mono-propellant MPGG, solid propellant SPGG and hybrid propellant HPGG as shown in Fig. 1. Another classification is made according to the nozzle type as sub-critical (operating pressure up to 50 bar) and super critical (operating pressure up to 200 bar). Figure 2 shows these types.

In SPGG, the gases generated pass through a cleaner and cooler to purify combustion gases from solid particles and reduce their temperature below $1500 \mathrm{~K}$. The general schematic diagram of SPGG is presented in Fig. 1a.

Figure 3 describes several configurations of SPGG commonly used as follows [3]:

- SPGG without cooling, Fig. 3a; this system is mainly suitable for relatively short durations, the regulator dumps excess gas overboard, for which a vent line must be provided. As an alternate, an orifice may be installed in place of the regulator.

- SPGG with solid coolant, Fig. $3 \mathrm{~b}$; the hot gas $\left(\approx 1300^{\circ} \mathrm{C}\right)$ is cooled as it passes through a bed of solid material (ammonium nitrate) by decomposition or sublimation. Thus, the cooling process simultaneously results in additional pressurization gas $\left(\mathrm{CO}, \mathrm{CO}_{2}\right.$, and $\mathrm{H}_{2} \mathrm{O}$ with temp. above $120^{\circ} \mathrm{C}$.). The gas then passes through a filter and is regulated to duct into propellant tanks.

\footnotetext{
Egyptian Armed Forces, Egypt.

$\dagger \quad$ Libyan Armed Forces, Libya, wesambashir@yahoo.com .
} 
- SPGG with azide cooling pack, Fig. 3c; cools hot gas by passing it through a bed of azide material that decomposes and yields essentially pure nitrogen with a limited metal particles. The gas is filtered to remove any remaining particles, regulated and pressurized at temperature less than $320^{\circ} \mathrm{C}$.

- Helium system with SPGG heating, Fig. 3d; consists of a high pressure helium tank with a SPGG mounted internally, a filter, and a pressure regulator. The solid propellant grain provides both heat and additional pressurant gas. This system needs a relatively large high pressure storage tank.

The SPGG can be utilized for pumping and gas turbine drive, liquid propellant feed system, moving actuators and mechanisms, separation units, hot air balloons, deploy airbags, electric power generation for missiles, thrust vector control, etc.

The main characteristics of SPGGs are fast operation, limited time of operation, high power generated, long time of storage (10-15 year), relatively small burning rate (0.3$10 \mathrm{~mm} / \mathrm{s}$ ) [2] and simple design with small size.

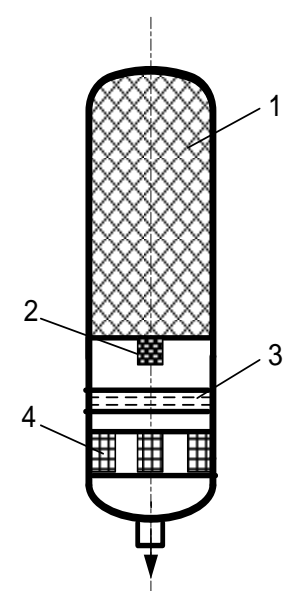

(a) SPGG

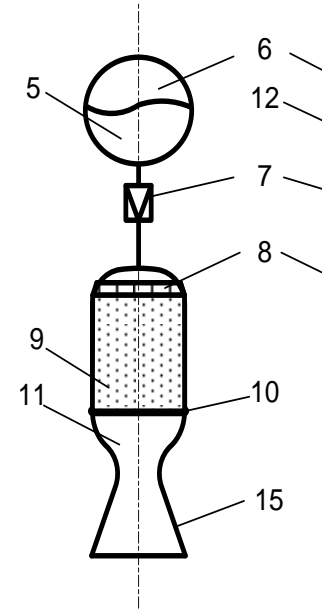

(b) MPGG

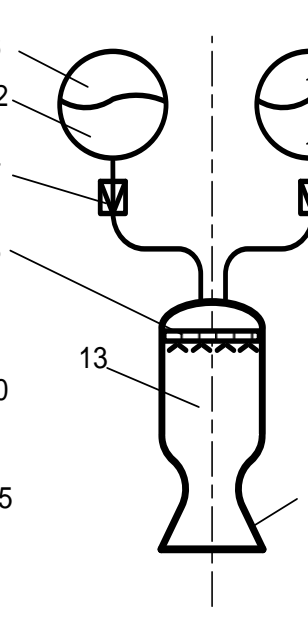

(c) LPGG

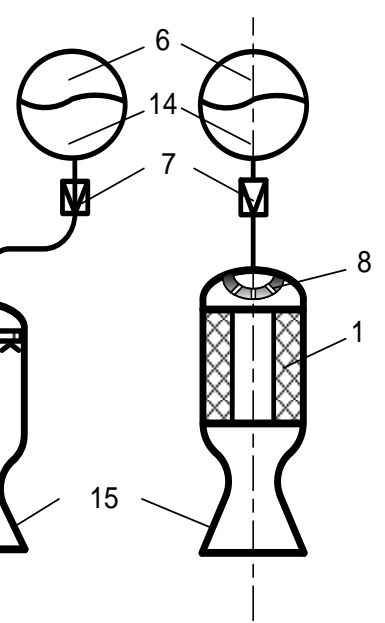

(d) HPGG

Fig. 1 Schematic of GGs with different propellant types

1-solid propellant, 2-igniter, 3-filter, 4-coolant, 5-mono-propellant, 6-high pressure gas, 7-control valve, 8-injection head, 9- catalytic-pack, 10-grid, 11-output hot gas, 12-fuel, 13-combustion (ox $+\mathrm{fu})$, 14-oxidizer, 15-nozzle part

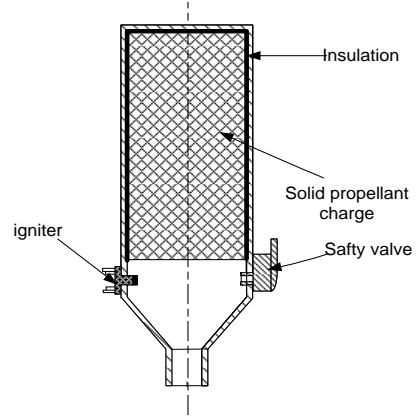

(a) Sub-critical SPGG

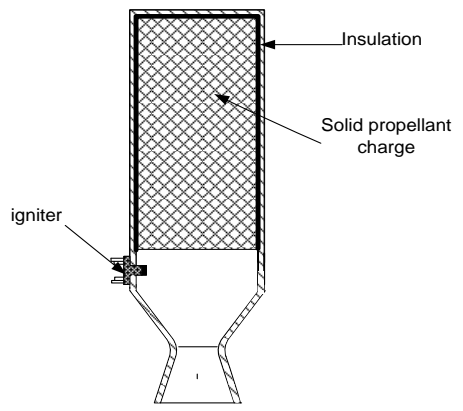

(b) Super-critical SPGG

Fig. 2 Schematic of sub-critical and super-critical SPGGs 
Design objective for operational SPGG may be summarized as:

- Ability to produce gases safety, with required properties (temperature, pressure, nonexplosive, harmless), in a compact unit at the required mass flow rate,

- Ability to start and operate smoothly without pressure oscillations,

- Ability to produce combustion gases free of solid particles.

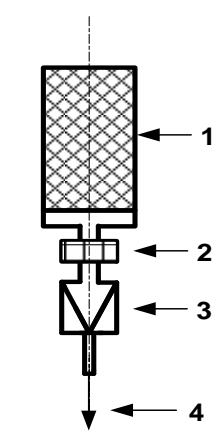

(a) SPGG without
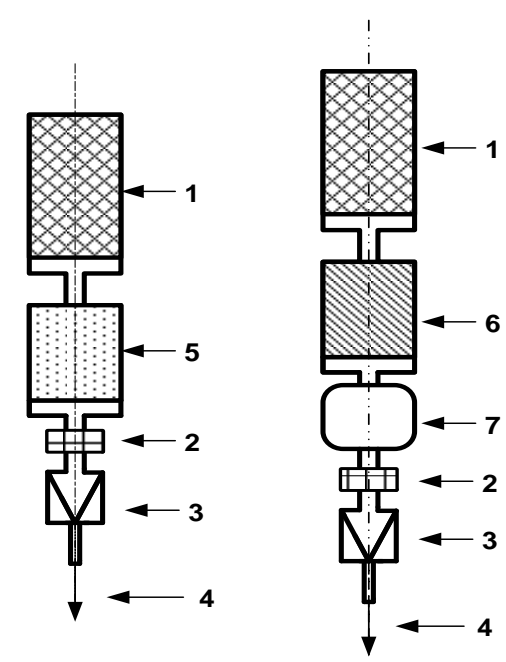
(b) SPGG solid
coolant

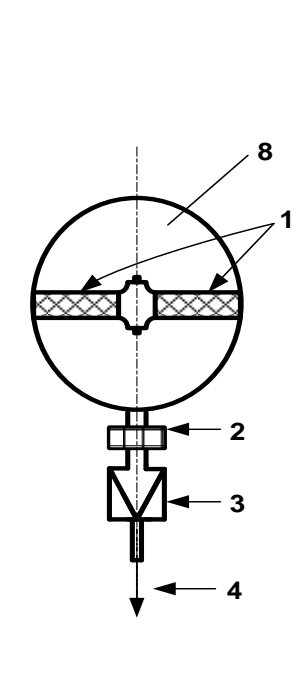
(c) SPGG with azide cooling
and decomposition pack (d) Helium system with

Fig. 3 SPGG systems

1- solid propellant charge, 2- filter, 3- pressure-relief type regulator,

4- exhaust gases, 5- solid coolant, 6- azide pack (Decomposing and coolant), 7- pure nitrogen, 8- high pressure helium.

\section{The Main Features of SPGG}

The main advantages of SPGG's are summarized as;

- Simplicity and integrity of construction and mass in consequence of a small volume of the needed SP charge,

- Stability of operation of the super-critical type and on safe-component and,

- They do not require high technology SP and hardware.

The drawbacks of the SPGG are:

- High combustion gas temperature of SP $(1500 \div 2500)^{\circ} \mathrm{C}$ which causes heating of the constructional parts,

- Temperature loss of the gases (up to $500 \div 1000)^{\circ} \mathrm{C}$ using coolant element,

- The sub-critical SPGG type needs safety valve,

- For a longer duration, high thickness of insulation is required and restricted time of storage.

The main vital purpose of GGSP is to produce high amount of with low temperature and without solid particle. A Large variety of propellants have been used to generate hot gas with solid trashes. The SP can be used as free-standing grain or case-bonded grain, the majority is free-standing for easy replacing after expiry date. 
The inhibitor (restrictor) is very significant for SPGG design, the SP is used usually fuel rich to achieve low combustion temperature with certain characteristics of combustion index, temperature sensitivity coefficient and chemical composition.

The SP charge types and shapes vary according the type of applications. In this paper, the end-burning GGSP can be modified and controlled by initial convex burning surface.

Special grain geometries that are used with SPGG are shown in Fig. 4, the shapes include convex end Fig. 4a, flat end Fig. 4b) and compound end burning Fig. 4c. Detail design and analysis of SPGG geometry are described in [4].

The GG solid propellant is designed to fulfill given main task, i.e. to secure the chamber pressure $\mathrm{P}_{\mathrm{c}}=\mathrm{P}(\mathrm{t})$, or required mass flow rate of combustion gases. The character of task allocated therefore demands respective geometric shape of SP charge. The grain main dimensions are introduced in Fig. 5.

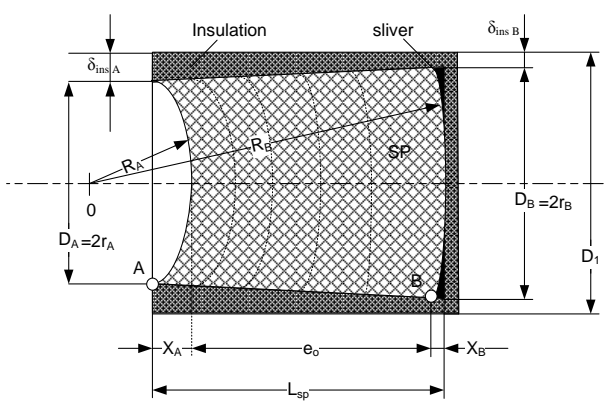

(a) convex shape

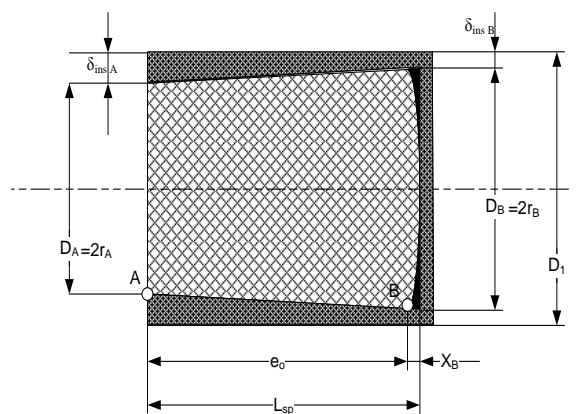

(b) flat shape

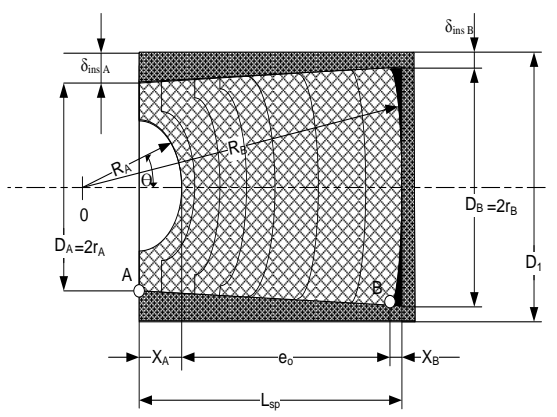

(c) compound shape

Fig. 4 SPGG front of the burning charge

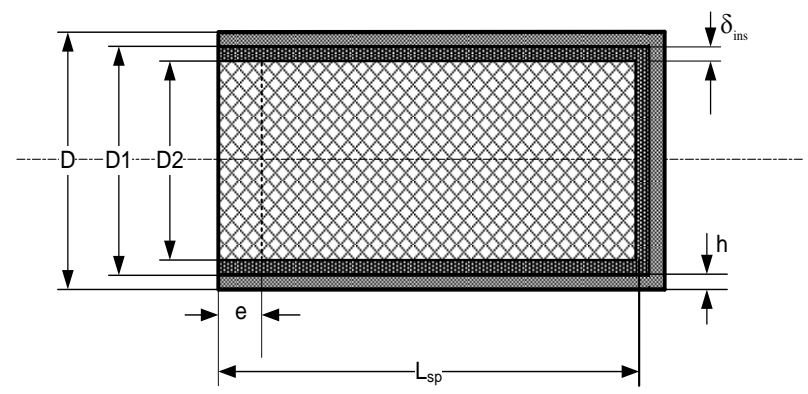

$\mathrm{D}=$ outer diameter of the SPGG cch,

$\mathrm{D}_{1}=$ inner diameter of the SPGG cch,

$\mathrm{D}_{2}=\mathrm{SP}$ grain diameter,

$\mathrm{e}=$ increment burnt thickness,

$\mathrm{L}_{\mathrm{sp}}=\mathrm{SP}$ grain length,

$\mathrm{h}=$ wall thickness of the SPGG cch.

Fig. 5 SPGG end burning grain 
The fundamental assumptions for the end burning surface combustion of the solid propellant are: [2]

- The penetration depth of the temperature profile is small compared to the web thickness of the propellant charge,

- The temperature gradient in the axial direction is small compared to the gradients in the normal direction,

- The effect of all thermal stress due to conduction heat transfer is neglected.

Under these conditions, the burning rate is commonly expressed as[2]:

$$
\mathrm{r}=\mathrm{r}_{\mathrm{o}} \cdot \mathrm{e}^{\mathrm{K}_{\mathrm{T}}\left(\mathrm{T}_{\mathrm{sp}}-\mathrm{T}_{\mathrm{N}}\right)} \cdot \mathrm{P}_{\mathrm{c}}^{\mathrm{n}}
$$

where $\mathrm{r}=$ linear burning rate of the propellant $[\mathrm{m} / \mathrm{s}], \mathrm{r}_{\mathrm{o}}=$ constant, $\mathrm{K}_{\mathrm{T}}=$ temperature sensitivity of propellant $\left[{ }^{\circ} \mathrm{C}\right], \mathrm{T}_{\mathrm{sp}}=$ temperature of propellant before burning $\left[{ }^{\circ} \mathrm{C}\right], \mathrm{T}_{\mathrm{N}}=$ some reference temperature $\left[{ }^{\circ} \mathrm{C}\right]$ and $\mathrm{n}=$ burning rate pressure exponent

The rate of generation of combustion gases from $\mathrm{SP}, \dot{m}_{\text {gen }}$ can be expressed as:

$$
\dot{m}_{g e n}=A_{b u} r \rho_{s p}
$$

where $\rho_{s p}=$ the SP density and $\mathrm{A}_{\mathrm{bu}}=$ the burning surface area.

\section{Internal Ballistic Model}

Pressure-time history of the end-burning grain combustion is evaluated during different phases of operation: ignition, burning and exhaust phases. The internal ballistics of SPGG combustion is approximately similar to that of SPRM.

The solution of internal ballistics of SPGG is attained via applying the basic laws of thermo chemistry, thermo dynamics and hydromechanics of gases.

Before coming to the explanation of main equations, it is necessary to define some basic parameters, which play an important role in the internal ballistics of SPGG operations.

\subsection{Equilibrium Pressure}

The equilibrium pressure $\left(\mathrm{P}_{\text {eq }}\right)$ is the pressure inside the combustion chamber in the steady state condition. The value of this pressure is determined by equating the rate of generated gas $\dot{m}_{\text {gen }}$ Eq. (2) to the gas mass flow rate discharged through nozzle $\dot{m}_{D}$ [2].

$$
\begin{gathered}
\dot{m}_{g e n}=\dot{m}_{D} \\
\mathrm{P}_{\mathrm{eq}}=\left(\frac{\rho_{s p} a \sqrt{R T_{c}}}{\Gamma} \frac{\mathrm{A}_{\mathrm{bu}}}{\mathrm{A}_{\mathrm{cr}}}\right)^{\frac{1}{1-n}}=\left(\rho_{s p} a c^{*} K_{I}\right)^{\frac{1}{1-n}}
\end{gathered}
$$

where $c^{*}=$ characteristics velocity, $K_{I}=A_{b u} / A_{c r}$ blocking factor and $\Gamma=(\gamma)^{\frac{1}{2}}\left(\frac{2}{\gamma+1}\right)^{\frac{\gamma+1}{2(\gamma-1)}}$ function of adiabatic exponent $\gamma$.

Reference to Fig. 5, the initial burning surface has the simplest form $\mathrm{A}_{\mathrm{bu}(\mathrm{i})}=\frac{\pi}{4} D_{2}^{2}$. However, during operation, the following relation holds for the burning surface area:

$$
\mathrm{A}_{\mathrm{bu}}=\frac{P_{e q}{ }^{1-n} \mathrm{~A}_{\mathrm{cr}}}{c^{*} a \rho_{s p}}
$$




\subsection{Operating Pressure}

Typical preliminary studies consider average operating pressure on a preliminary basis in establishing a Maximum Expected Operating Pressure (MEOP) for the SPGG. An estimate of the pressure is made for the primary purpose of determining a nozzle throat area, propellant weight for initial grain dimensions and burning rate for web fraction.

Practically for the first estimation and preliminary dimensioning of grain and nozzle geometry, the choice of average operating pressure at ambient temperature depends on:

1. Dimensions of the motor to be designed with particular reference to be diameter.

2. Experience and comparison with similar motors already developed.

3. Intuitive judgment of the designer.

Operation of SPGG depends on the combustion products emitted from burning solid propellant charge. The biggest part of the products goes through the nozzle part, to get high velocity or force of combustion gases, while the smallest part of combustion products remains inside the GG chamber and creates internal high pressure and temperature, needed for continuity solid propellant charge burning.

Figure 6 illustrates an end burning SPGG where the largest amount combustion gases passes through the nozzle and the smallest amount accumulates inside to maintain the pressure and temperature in cch.
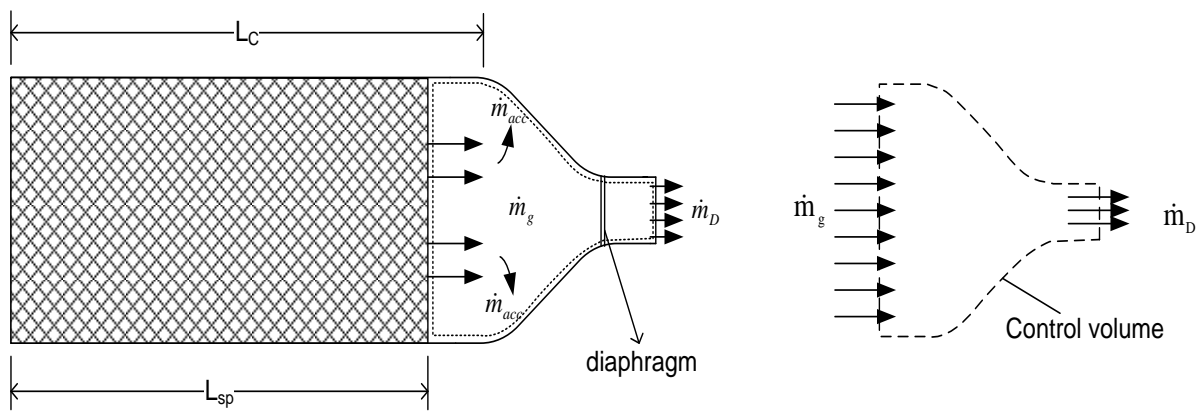

Fig. 6 Mass balance of gases in the end burning SPGG

By applying the law of conservation of mass in the chamber, the accumulate combustion gases rate inside free volume of combustion chamber $\dot{m}_{a c c}$ can be written as [2].

$$
\frac{d \rho V}{d t}=\dot{m}_{g}-\dot{m}_{D}
$$

The assumptions for internal ballistic solution are:

1. The combustion gases are homogenous;

2. The combustion gases obey the perfect gas law;

3. The specific heat, gas velocity, pressure and specific mass are uniform across any section normal to the axis;

4. Temperature of the combustion gases are constants;

5. No heat transfer through the cch and nozzle walls (adiabatic flow);

6. The combustion gases form a one dimensional steady flow and isentropic with no fraction;

7. The frozen flow in nozzle.

The discharge mass flow rate can be defined as

$$
\dot{m}_{D}=A_{c r} P_{c}\left(\frac{2}{R T_{c}}\right)^{\frac{1}{2}} \psi \quad \psi=\left(\frac{P_{c r}}{P_{c}}\right)^{\frac{1}{\gamma}}\left\{\frac{\gamma}{\gamma-1}\left[1-\left(\frac{P_{c r}}{P_{c}}\right)^{\frac{\gamma-1}{\gamma}}\right]\right\}^{\frac{1}{2}}
$$


where $\psi$ is the discharge function depending only on $\gamma$ and the pressure ratio between throat and chamber $\left(\mathrm{P}_{\mathrm{cr}} / \mathrm{P}_{\mathrm{c}}\right)$. The $\psi$ has a maximum value at $\mathrm{d} \psi / \mathrm{d}\left(\mathrm{P} / \mathrm{P}_{\mathrm{c}}\right)=0$ and then the critical pressure ratio when sonic velocity is reached at the throat.

$\frac{d \psi}{d\left(P / P_{c}\right)}=\left(\frac{\gamma}{\gamma-1}\right)^{\frac{1}{2}} \frac{1}{2}\left[\left(\frac{P}{P_{c}}\right)^{\frac{2}{\gamma}}-\left(\frac{P}{P_{c}}\right)^{\frac{\gamma+1}{\gamma}}\right]^{-\frac{1}{2}}\left[\frac{2}{\gamma}\left(\frac{P}{P_{c}}\right)^{\frac{2-\gamma}{\gamma}}-\frac{\gamma+1}{\gamma}\left(\frac{P}{P_{c}}\right)^{\frac{1}{\gamma}}\right]=0$

Wherefrom:

$$
\frac{2}{\gamma}\left(\frac{P}{P c}\right)^{\frac{2-\gamma}{\gamma}}-\frac{\gamma+1}{\gamma}\left(\frac{P}{P c}\right)^{\frac{1}{\gamma}}=0 \quad \text { or } \quad \frac{P_{c r}}{P_{c}}=\left(\frac{2}{\gamma+1}\right)^{\frac{\gamma}{\gamma-1}}
$$

This is the critical pressure ratio at which sonic velocity just exists in the throat and the discharge function $\psi$ has reached a maximum of

$$
\psi_{\max }=\left(\frac{\gamma}{\gamma+1}\right)^{\frac{1}{2}}\left(\frac{2}{\gamma+1}\right)^{\frac{1}{\gamma-1}}
$$

The result shows that, the discharge function $\psi$ depends only on $\gamma$ in the case of critical conditions.

For the sub-critical case, the discharge function remains

$$
\psi=\left(\frac{P_{c r}}{P_{c}}\right)^{\frac{1}{\gamma}}\left\{\frac{\gamma}{\gamma-1}\left[1-\left(\frac{P_{c r}}{P_{c}}\right)^{\frac{\gamma-1}{\gamma}}\right]\right\}^{\frac{1}{2}}
$$

\subsection{SPGG Ignition Phase}

The time required to build up the chamber pressure is the sum of time $t_{1}$ during which the pressure increase from $\mathrm{P}_{\mathrm{c} 1}$ to $P_{c r} /(2 / \gamma+1)^{\frac{\gamma}{\gamma-1}}$ and the time $\mathrm{t}_{2}$ during which the chamber pressure increases to $P_{c}$ as shown in Fig. 7. The efflux during the $1^{\text {st }}$ and $2^{\text {nd }}$ intervals (subcritical and super-critical) depends on $\mathrm{P}_{\mathrm{cr}} / \mathrm{P}_{\mathrm{c}}$ : There are two design cases namely, the nozzle is closed by a membrane or opened during ignition phase.

\subsubsection{Closed nozzle by diaphragm}

If the nozzle is closed for a moment during ignition by a membrane (diaphragm) and no mass flow through the nozzle takes place, the following equation is applied

$$
\dot{m}_{a c c}=\dot{m}_{g} \quad \frac{d \rho_{c} V_{f r}}{d t}=A_{b u} \rho_{s p} a P_{c}^{n}
$$

The derivative of the accumulated gas mass in the cch free volume can be expressed as

$$
\frac{d \rho_{c} V_{f r}}{d t}=V_{f r} \frac{d \rho_{c}}{d t}+\rho_{c} \frac{d V_{f r}}{d t}
$$

Where $V_{f r}$ is the instantaneous volume in the cch of SPGG and $\rho_{c}$ is the instantaneous density of the combustion gas.

The free volume is a function of time due to combustion of the SP by

$$
V_{f r}=V_{c}-\frac{m_{s p(i)}}{\rho_{s p}}+\int_{0}^{t} A_{b u} a P_{c}^{n} d t
$$




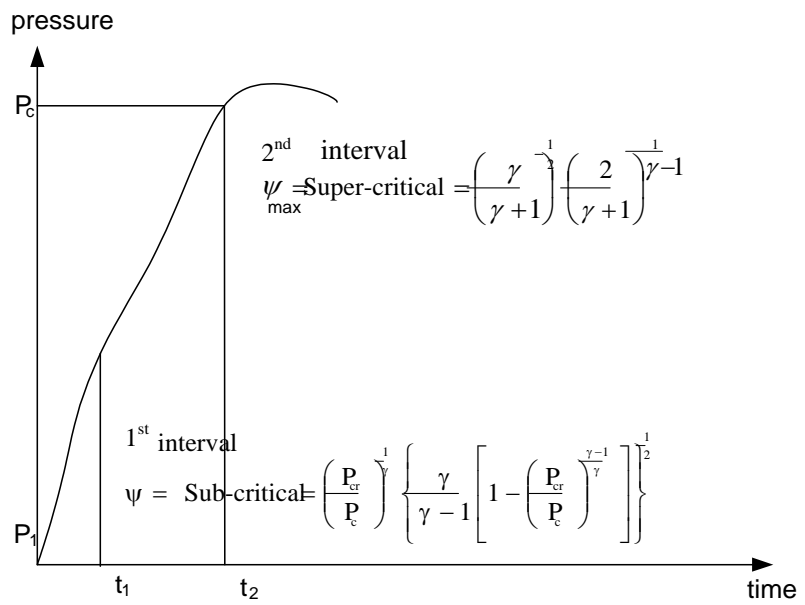

Fig. 7 SPGG pressure-time curve transient (Initial pressure rise phase)

where $\mathrm{V}_{\mathrm{c}}$ the volume of the empty $\mathrm{cch}, \mathrm{m}_{\mathrm{sp}(\mathrm{i})}$ the initial mass of propellant and $\int_{0}^{t} A_{b u} a P_{c}^{n} d t$.the volume of consumed propellant.

Since the chamber volume and the initial mass of the propellant are constant, then

$$
\left(V_{c}-\frac{m_{s p(i)}}{\rho_{s p}}+\int_{0}^{t_{1}} A_{b u} a P_{c}^{n} d t\right) \frac{d P_{c}}{d t}=R T_{c} A_{b u} \rho_{s p} a P_{c}^{n}\left(1-\frac{\rho_{c}}{\rho_{s p}}\right)
$$

In this relation the $\rho_{c}$ is less than one or two percent of the $\rho_{s p}$, thus it can be neglected.

$$
\left(V_{c}-\frac{m_{s p(i)}}{\rho_{s p}}+\int_{0}^{t_{1}} A_{b u} a P_{c}^{n} d t\right) \frac{d P_{c}}{d t}=R T_{c} A_{b u} \rho_{s p} a P_{c}^{n}
$$

At a certain pressure, the membrane bursts and the efflux begins.

A quasi-steady flow will be assumed, i. e., the discharge rate is determined at any given moment by the equations for steady flow. Here, Eq. (5) is valid

$$
\left(V_{c}-\frac{m_{s p(i)}}{\rho_{s p}}+\int_{0}^{t_{2}} A_{b u} a P_{c}^{n} d t\right) \frac{d P_{c}}{d t}=R T_{c} A_{b u} \rho_{s p} a P_{c}^{n}-A_{c r} P_{c} \psi\left(2 R T_{c}\right)^{\frac{1}{2}}
$$

Usually, when the diaphragms burst, the chamber pressure greatly exceeds the critical pressure,

$$
\begin{gathered}
\text { i.e. } \frac{P_{c r}}{P_{c}} \leq\left(\frac{2}{\gamma+1}\right)^{\frac{\gamma}{\gamma-1}} \text { and } \psi=\psi_{\max } \text { Then, } \\
\left(V_{c}-\frac{m_{s p(i)}}{\rho_{s p}}+\int_{0}^{t_{2}} A_{b u} a P_{c}^{n} d t\right) \frac{d P_{c}}{d t}=R T_{c} A_{b u} \rho_{s p} a P_{c}^{n}-(\gamma)^{\frac{1}{2}}\left(\frac{2}{\gamma+1}\right)^{\frac{\gamma+1}{2(\gamma-1)}} A_{c r} P_{c}\left(R T_{c}\right)^{\frac{1}{2}}
\end{gathered}
$$

\subsubsection{Open end nozzle}

Eq. (10) gives the discharge function until the critical pressure ratio is reached $P_{c r} / P_{c} \geq(2 / \gamma+1)^{\frac{\gamma}{\gamma-1}}$, then in the sub-critical phase, the differential Eq. (18) will be

$$
\left(V_{c}-\frac{m_{s p(i)}}{\rho_{s p}}+\int_{0}^{t_{1}} A_{b u} a P_{c}^{n} d t\right) \frac{d P_{c}}{d t}=R T_{c} A_{b u} \rho_{s p} a P_{c}^{n}-A_{c r} P_{c}\left(\frac{P_{c r}}{P_{c}}\right)^{\frac{1}{\gamma}}\left\{\frac{2 \gamma}{\gamma-1} R T_{c}\left[1-\left(\frac{P_{c r}}{P_{c}}\right)^{\frac{\gamma-1}{\gamma}}\right]\right\}^{\frac{1}{2}}
$$


For the super-critical phase $P_{c r} / P_{c} \leq(2 / \gamma+1)^{\frac{\gamma}{\gamma-1}}$ and $\psi=\psi_{\max }$, then Eq. (18) will be valid.

\subsection{Pseudo Equilibrium Operation}

The Eq. (18) describes the development of the chamber pressure as a function of time at super-critical phase conditions and $r d t=d y$ then,

$$
\begin{gathered}
\frac{d P_{c}}{d y}=\frac{1}{r}\left(\frac{\Gamma^{2} A_{b u} \rho_{s p} a}{V_{f r} C_{D}{ }^{2}} P_{c}^{n}-\frac{\Gamma^{2} A_{c r}}{V_{f r} C_{D}} P_{c}\right) \\
P_{c}=\left(\left(P_{e q}\right)^{1-n}-\frac{a V_{f r}}{A_{c r} \Gamma^{2} C^{*}} \frac{d P}{d y}\right)^{\frac{1}{1-n}}
\end{gathered}
$$

The differential can be carried out

$$
\frac{d P}{d y}==\frac{\mathrm{P}_{\mathrm{eq}}}{1-n}\left(\frac{1}{A_{b u}}\left(\frac{d A_{b u}}{d y}\right)\right)
$$

Eq. (20) and Eqs. (21) (22) are solved numerically by two different techniques.

\subsection{Chamber Pressure Decay}

Figure 8 shows the pressure decay in the transient tail off (exhaust) phase of the pressure-time history.

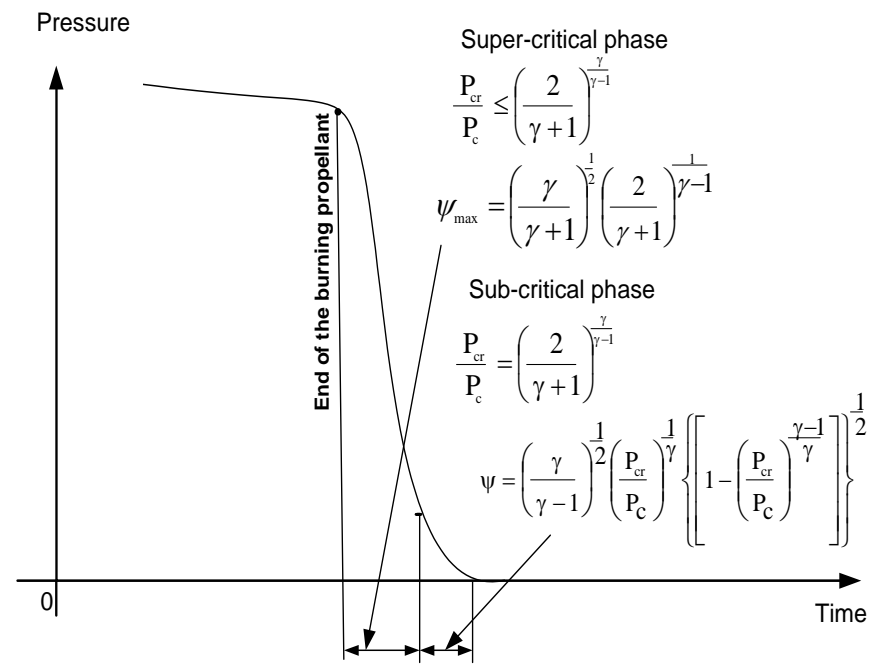

Fig. 8 SPGG pressure-time curve transient: Tail off (exhaust) phase

After burnout of the SP, no source of combustion gases, the $\mathrm{P}_{c}, \rho_{c}$ and $\mathrm{T}_{\mathrm{c}}$ that exist are considered as initial conditions. The law of conservation of mass is applied as:

$$
\begin{gathered}
\dot{m}_{a c c}=-\dot{m}_{D} \quad \frac{d \rho V_{c(f)}}{d t}=-\dot{m}_{D} \\
V_{c(f)} \frac{d}{d t} \frac{\rho}{\rho_{c}}=-\frac{\rho}{\rho_{c}} A_{c r}\left(2 R T_{c}\right)^{\frac{1}{2}}\left(\frac{T}{T_{c}}\right)^{\frac{1}{2}} \psi
\end{gathered}
$$

Following the adiabatic relation and arranging gives 


$$
\frac{d}{d t}\left(\frac{P}{P_{c}}\right)=-\frac{A_{c r}}{V_{c(f)}} \gamma\left(\frac{P}{P_{c}}\right)^{\frac{3 \gamma-1}{2 \gamma}} \psi\left(2 R T_{c}\right)^{\frac{1}{2}}
$$

This $1^{\text {st }}$ order differential equation can be solved by separation of the variables as follows

$$
\frac{d\left(P / P_{c}\right)}{\psi\left(P / P_{c}\right)^{\frac{3 \gamma-1}{2 \gamma}}}=-\frac{A_{c r}}{V_{c(f)}} \gamma\left(2 R T_{c}\right)^{\frac{1}{2}} d t
$$

Since the discharge function $\Psi$ depends on the pressure ratio, two cases have to be distinguished, the supercritical and the sub-critical conditions.

\subsubsection{Decay during super-critical phase}

For the supercritical condition, the pressure ratio is as developed previously as:

$$
\begin{gathered}
\frac{P_{c r}}{P_{c}} \leq\left(\frac{2}{\gamma+1}\right)^{\frac{\gamma}{\gamma-1}} \text { and } \psi_{\text {max }}=\left(\frac{\gamma}{\gamma+1}\right)^{\frac{1}{2}}\left(\frac{2}{\gamma+1}\right)^{\frac{1}{\gamma-1}} \text {, the boundary conditions are: } \\
\mathrm{t}=0 \rightarrow \frac{P}{P_{c}}=1 \quad \mathrm{t}=\mathrm{t}_{1} \rightarrow \frac{P}{P_{c}}=\frac{P}{P_{c}}
\end{gathered}
$$

Then Integrated Eq. (27) yields;

$$
\int_{1}^{P / P_{c}} \frac{d\left(P / P_{c}\right)}{\psi\left(P / P_{c}\right)^{\frac{3 \gamma-1}{2 \gamma}}}=-\frac{A_{c r}}{V_{c(f)}} \gamma\left(2 R T_{c}\right)^{\frac{1}{2}} t_{1}
$$

Eq. (27) after integrating and rearranging, expressing the chamber pressure explicitly as a function of time becomes

$$
\frac{P}{P_{c}}=\left[1+\frac{A_{c r} t_{1}}{V_{c}} \frac{\gamma-1}{2}\left(\frac{2}{\gamma+1}\right)^{\frac{\gamma+1}{2(\gamma-1)}}\left(\gamma R T_{c}\right)^{\frac{1}{2}}\right]^{-\frac{2 \gamma}{\gamma-1}}
$$

Eq. (28) shows that the efflux at supercritical condition is independent of $\mathrm{P}_{\mathrm{cr}} / \mathrm{P}_{\mathrm{c}}$.

\subsubsection{Decay during sub-critical phase}

Eq. (27) is also valid which is with the sub-critical discharge function as Eq. (10) and pressure ratio as $\frac{P_{c r}}{P_{c}} \geq\left(\frac{2}{\gamma+1}\right)^{\frac{\gamma}{\gamma-1}}$, taking into account the initial condition

$$
\mathrm{t}=0 \rightarrow \frac{p}{P_{c}}=\frac{P_{c r}}{P_{c}[2 /(\gamma+1)]^{\frac{\gamma}{\gamma-1}}} \quad \quad \mathrm{t}=\mathrm{t}_{3} \rightarrow \frac{\mathrm{P}}{\mathrm{P}_{\mathrm{c}}}=\frac{\mathrm{P}}{\mathrm{P}_{\mathrm{c}}}
$$

Finally the equation is

$$
\frac{A_{c r} t_{3} \gamma\left\{[2 \gamma /(\gamma-1)] R T_{c}\right\}^{\frac{1}{2}}}{V_{c}}=-\left(\frac{P_{c r}}{P_{c}}\right)^{-\frac{1}{\gamma}} \int_{P_{c r} / P_{c}[2 /(\gamma+1)]^{\frac{\gamma}{\gamma-1}}}^{P / P_{c}} \frac{\left(P / P_{c}\right)^{-\frac{3(\gamma-1)}{2 \gamma}} d\left(P / P_{c}\right)}{\left[-\left(P_{c r} / P_{c}\right)^{\frac{\gamma-1}{\gamma}}\left(P / P_{c}\right)^{-\frac{\gamma-1}{\gamma}}\right]^{\frac{1}{2}}}
$$

The above integral can be calculated only by the numerical method.

From Eq. (23) the super-critical phase can be solved by [2]: 


$$
\begin{aligned}
V_{c(f)} \frac{d \rho}{d t} & =-\rho A_{c r}(R T)^{\frac{1}{2}} \Gamma \\
\frac{d P_{c}}{P_{c}} & =-\frac{\Gamma^{2} A_{c r} c^{*}}{V_{c(f)}} d t
\end{aligned}
$$

After integrating and setting $t_{b}=0$ then the super-critical phase decay time becomes

$$
t_{f}=\frac{V_{c(f)}}{\Gamma^{2} A_{c r} C^{*}} \cdot \ln \left(\frac{P_{f}}{P_{c}}\right)
$$

\section{Computational and Experimental Work}

Computer program was developed to solve pressure-time history and calculate performance (average pressure, burning rate, burning time, .etc.) for SPGG end burning grain with different shapes (convex, flat, compound).

The experimental work is to realize a functioning test SPGG, to predict the variation of pressure with time and compared to results obtained from theoretical computations.

In order to check the validity of the developed computer program, it is used to predict the variation of pressure with time and the other important parameters for the real SPGG, the experimental data were compared with results obtained from theoretical computation. The comparison has shown good agreement, which proves the validity of the developed program.

\subsection{Computer Programs}

Two programs were developed to perform done discussed, calculations in these different approaches. Data is manipulated through input and output files, beside the main program. The program computes, in SI system units.

\subsubsection{Computer program No.1}

Figure 9 describes the block diagram programs, the input file contains the SP basic dimension and characteristics, cch dimensions and basic performance of thermo-chemical parameters,

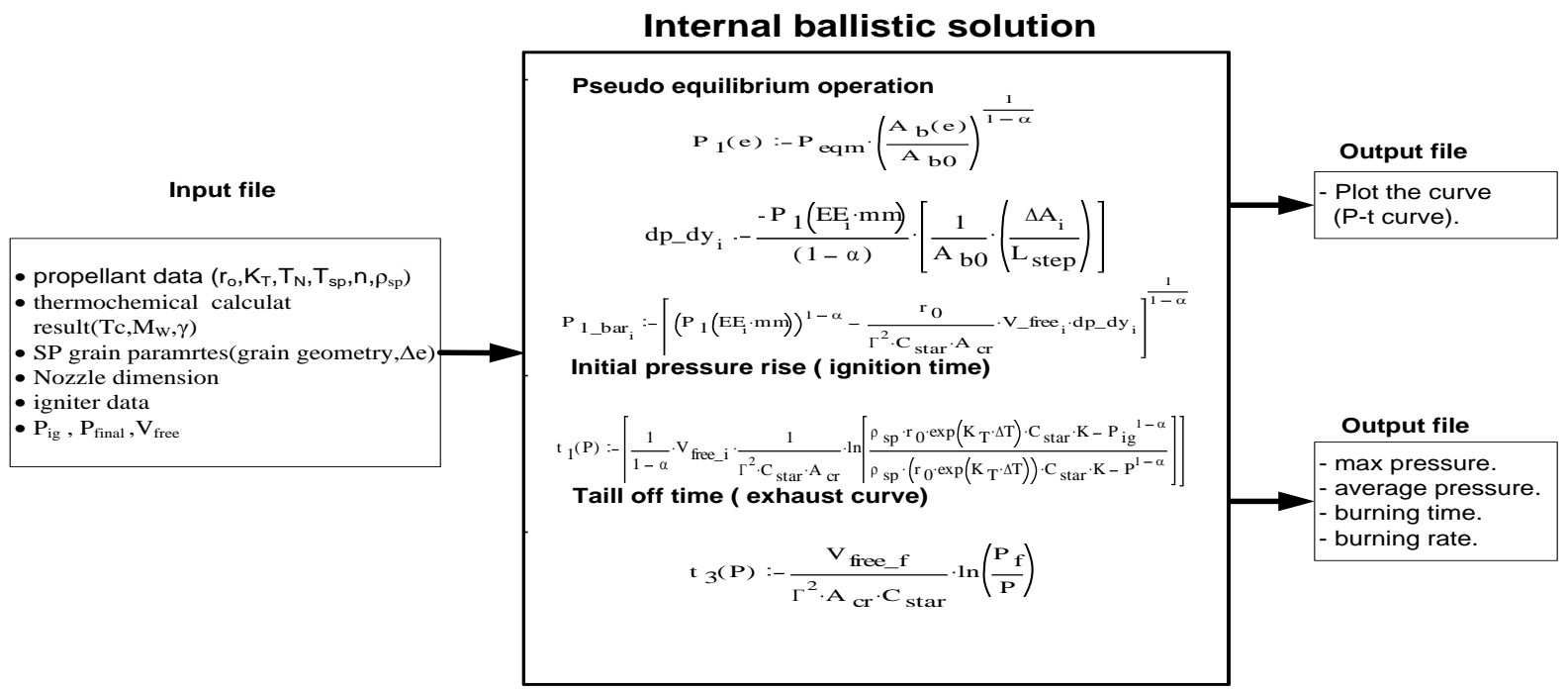

Fig. 9 Math-Cad Software (Program No:1) 
The main program solve three phases of pressure-time profile, each phase contains the certain assumption to satisfy operating phenomena. The solution strategy that has been adapted to determine the pressure history and performance can be described by solving each phase separately. The ignition phase is characterized by: zero burning surface, constant initial free volume, zero discharge mass flow rate and the rate at which the chamber pressure increases with time is relatively high.

The steady state phase generally occupies the longest time operation if compared with other phases. That phase starts directly after ignition while considering $\mathrm{y}=0$. The phase ends at the moment when the web thickness tends to zero. The prediction of pressure-time history is performed by mass conservation over very short time (or web thickness) intervals. Solution is obtained by iteration on chamber pressure equation to reach the equilibrium value. The equilibrium pressure changed with the rate of change of chamber pressure with depth of burning ( $\mathrm{dP} / \mathrm{dy}$ ), which functions of rate of change of burning are and free volume.

The exhaust phase, the SP combustion was completed, that is mean, stop combustion gases generated inside combustion chamber. The reminder of accumulation combustion gasses is simply exhausting (ejected) through nozzle section. In the other hands, that regime is characterized by: no SP combustion (no mass flow generated), constant free volume equal the combustion chamber volume and the rate of chamber pressure drops with time is relatively high.

Table 1 shows the input data while the calculated pressure-time curve is shown in Fig. 10.

Table 1 Input File Data

\begin{tabular}{l|c|l|c}
\hline \hline \multicolumn{1}{c|}{ Propellant data } & \multicolumn{1}{c}{ SP grain parameters } \\
\hline Initial burning rate coefficient, $\mathrm{r}_{\mathrm{o}}$ & $\begin{array}{c}0.00147 \times 10^{-4} \\
(\mathrm{~m} / \mathrm{sec}) /\left(\mathrm{P}_{\mathrm{c}}\right)^{\mathrm{n}}\end{array}$ & Inner cch diameter, $\mathrm{D}$ & $28(\mathrm{~mm})$ \\
\hline SP temp. sensitivity, $\mathrm{K}_{\mathrm{T}}$ & $0.0042\left(\mathrm{~K}^{-1}\right)$ & Outer SP grain diameter, $\mathrm{D}_{2}$ & $25(\mathrm{~mm})$ \\
\hline SP normal temper., $\mathrm{T}_{\mathrm{N}}$ & $293(\mathrm{~K})$ & Length of SP, $\mathrm{L}_{\mathrm{sp}}$ & $90(\mathrm{~mm})$ \\
\hline SP combustion temper., $\mathrm{T}_{\mathrm{sp}}$ & $293(\mathrm{~K})$ & Throat diameter, $\mathrm{D}_{\mathrm{cr}}$ & $1.0(\mathrm{~mm})$ \\
\hline Combustion index, $\mathrm{n}$ & 0.67 & Initial concave angle, $\mathrm{O}_{0}$ & $60(\mathrm{deg})$ \\
\hline Density of $\mathrm{SP} \rho_{\mathrm{sp}}$ & $1564\left(\mathrm{~kg} / \mathrm{m}^{3}\right)$ & \multicolumn{1}{c}{ igniter data } \\
\hline Temper. of combustion, $\mathrm{T}_{\mathrm{c}}$ & $1970(\mathrm{~K})$ & Igniter pressure, $\mathrm{P}_{\mathrm{ig}}$ & $75(\mathrm{bar})$ \\
\hline $\begin{array}{l}\text { Molecular weight of combustion } \\
\text { gases, } \mathrm{M}_{\mathrm{W}}\end{array}$ & $22.64(\mathrm{gm} / \mathrm{mol})$ & Initial free volume, $\mathrm{V}_{\text {free }}$ & $5\left(\mathrm{~cm}^{3}\right)$ \\
\hline Specific heat ratio, $\gamma$ & 1.22 & Final decaying pressure, $\mathrm{P}_{\text {final }}$ & $1.0(\mathrm{bar})$ \\
\hline \hline
\end{tabular}

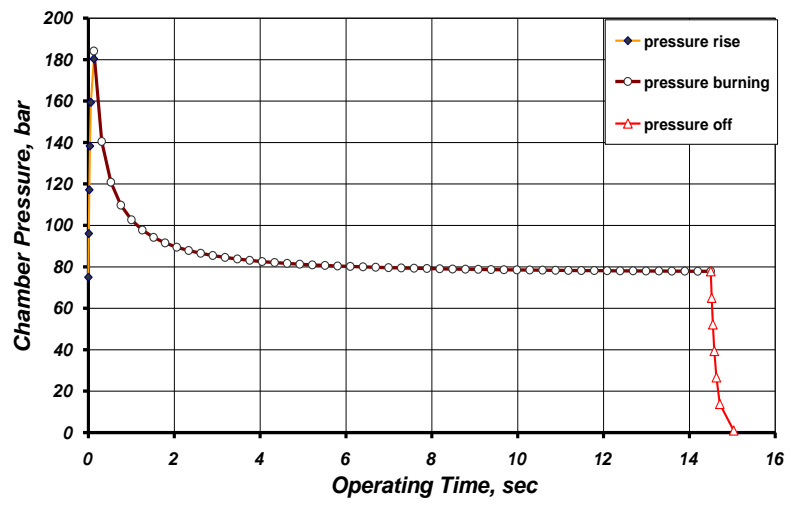

Fig. 10 Calculated pressure-time history, (program 1) 


\subsubsection{Computer program No. 2}

Figure 11 shows the schematic diagram for software program, the input file is smaller input file of Math-Cad program. The computer program described in this section is capable of calculating the pressure-time curve variation and performance by using conservation of mass Eq. (5), the propellant mass burned per unit time must be equal the sum of the change in gas mass per unit in the combustion chamber and the mass flowing through the nozzle per unit time. The main program solve three phases of pressure-time profile, ignition, pseudo equilibrium and tail-off phases by applied continuity equation under certain conditions for each phase.

The calculated pressure-time curve is shown in Fig. 12.

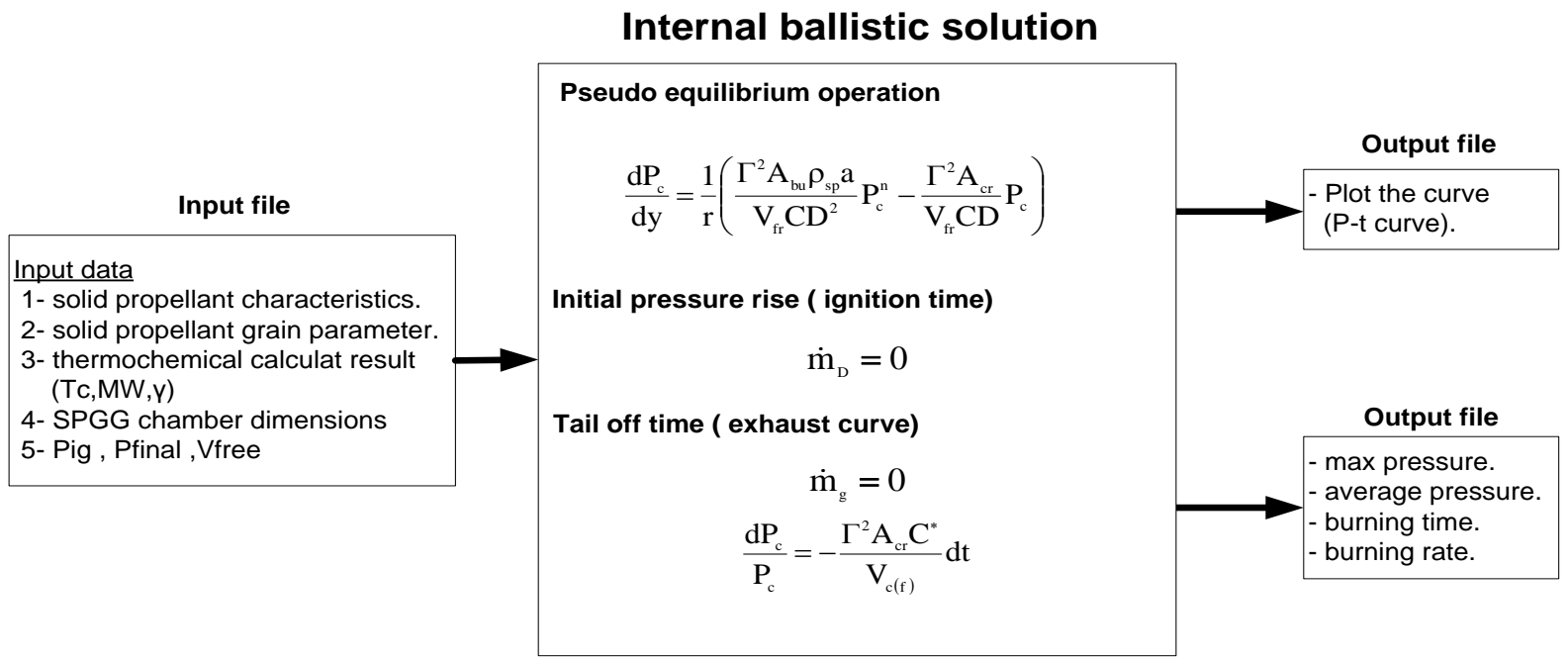

Fig. 11 Mat-Lab for Software (Program No.2)

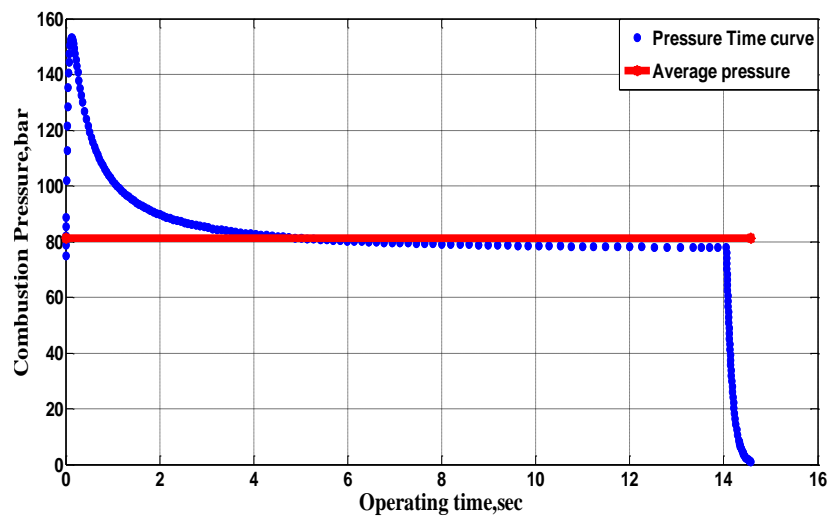

Fig. 12 Calculated pressure-time history, (program 2)

\subsection{Experimental Work}

The direct goal of the experimental work is to check the validity of the mathematical model and the developed computer programs through evaluating the performance of real SPGG end burning used with air defense missile shown in Fig.13. The static firing performed in the test facility considers a typical pressure-time diagram for SPGG as defined in Fig. 14. The exact definitions of the different times in this curve are, burning time $\left(t_{b}\right)$ and action time $\left(t_{a}\right)$. 
Burning time $\left(\mathrm{t}_{\mathrm{b}}\right)$ is well established as the interval form $10 \%$ max pressure to web burnout, usually taken as the aft tangent-bisector point. Action time $\left(\mathrm{t}_{\mathrm{a}}\right)$ typically is the time interval form $10 \%$ max pressure to $25 \% \overline{\mathrm{P}}_{\mathrm{av}}$ or $\mathrm{P}_{\min }$. The total time $\left(\mathrm{t}_{\mathrm{t}}\right)$ is the time interval from 0 to the aft pressure of 2 bar.

The mean chamber pressure is calculated as $\overline{\mathrm{P}}_{\mathrm{av}}=\frac{1}{\mathrm{t}_{\mathrm{b}}} \int_{0}^{\mathrm{t}_{\mathrm{b}}} \mathrm{Pdt}$

The average burning rate is determined according to $\mathrm{r}_{\mathrm{av}}=\mathrm{L}_{\mathrm{sp}} / \mathrm{t}_{\mathrm{bu}}$. The pressure time curves obtained from fire tests indicate that the gas generator is functioning properly. The ignition takes place without problems, the pressure reflects a stable and quite steady burning, the exhaust gases are clear and steady, the pressure decay is smooth and the required mass flow and burning time are satisfactory.

The records of pressure-time history of real three static firing tests at room temperature are shown in Fig. 15. Results are displayed in Table 2.

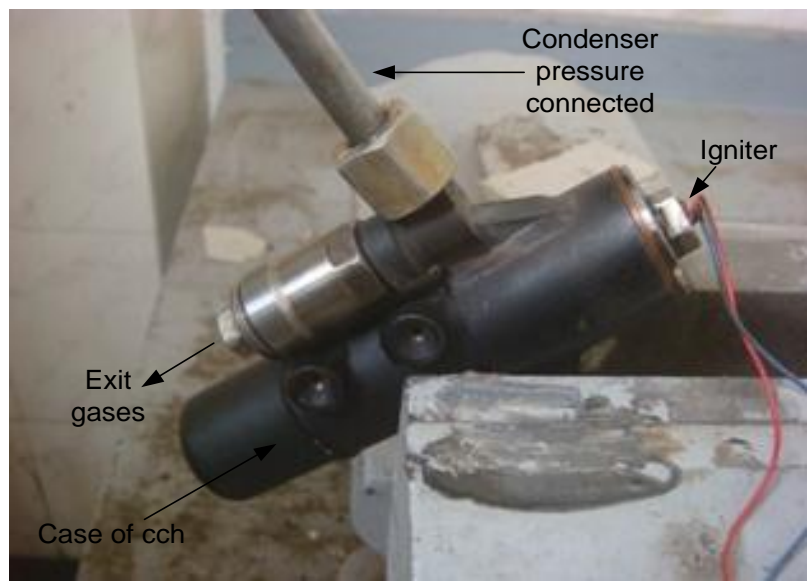

Fig. 13 Real SPGG (air defense missile)

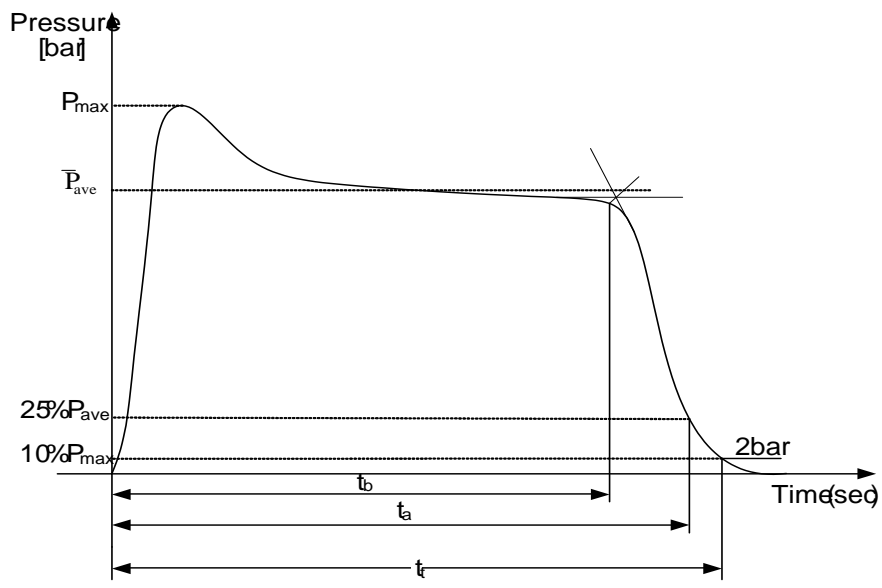

Fig. 14 Pressure-time profile for SPGG 

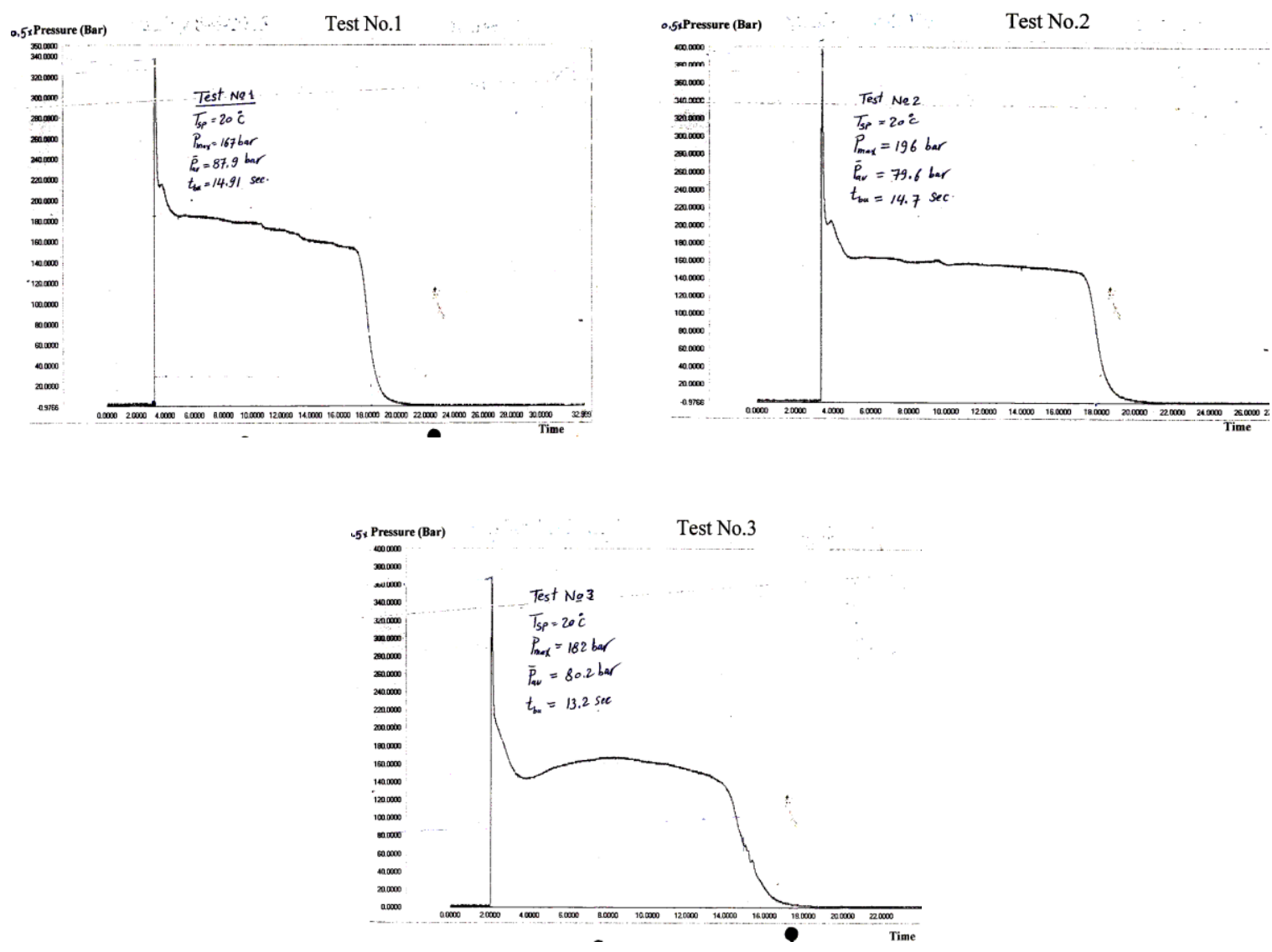

Fig. 15 SPGG experimental pressure with time operation

Table 2 Experimental static firing results of SPGG

\begin{tabular}{l|c|c|c|c}
\hline \hline \multirow{2}{*}{ Measured Parameter } & \multicolumn{4}{c}{ Experimental } \\
\cline { 2 - 5 } & Test1 & Test2 & Test3 & Average value \\
\hline Average pressure [bar] & 87.90 & 79.6 & 80.20 & 82.57 \\
\hline Maximum pressure [bar] & 167 & 196 & 182 & 181.67 \\
\hline Burning time [sec] & 14.91 & 14.70 & 13.20 & 14.27 \\
\hline Burning rate [mm/sec] & 6.03 & 6.12 & 6.81 & 6.32 \\
\hline \hline
\end{tabular}

\subsection{Comparison of Computer and Measurement Parameters}

The measured experimental data were compared with results obtained from theoretical computation. The comparison shows good agreement, as seen in Table 3, which proves the validity of the developed program, since the maximum error of the program No: 1 is generally less than $4 \%$ and program no:2 max error is equal 3\%. However, the error in maximum pressure that amounts to $15 \%$ in Mat-lab program output can be attributed to ignition phase assumptions.

It can be seen that the theoretical predictions are in good agreement with the test results and it is clear that it has the same behavior. Fortunately, the values of the calculated and measured performance parameters are approximately the same. 
Table 3 Comparison of computers and measured parameters

\begin{tabular}{l|c|c|c|c|c}
\hline \hline \multicolumn{1}{c|}{ Parameter } & $\begin{array}{c}\text { Average } \\
\text { Measured }\end{array}$ & Program 1 & $\begin{array}{c}\text { Average } \\
\text { error\% }\end{array}$ & Program 2 & $\begin{array}{c}\text { Average } \\
\text { error\% }\end{array}$ \\
\hline average pressure [bar] & 82.57 & 85.31 & 3.3 & 81.20 & 1.7 \\
\hline Maximum pressure [bar] & 181.67 & 184.08 & 1.3 & 153.37 & 15 \\
\hline Burning time [sec] & 14.27 & 14.75 & 3.4 & 14.58 & 2.2 \\
\hline Burning rate [mm/sec] & 6.31 & 6.10 & 3.3 & 6.17 & 2.2 \\
\hline \hline
\end{tabular}

\section{Conclusions}

The main advantages of SPGG's are summarized as; simplicity and integrity of construction and mass in consequence of a small volume of the needed. The main vital purpose of GGSP is to produce high amount of gas with low temperature and without solid particle (smokeless).

A survey of available constructional ideas and basic relations for solving the internal ballistic model for an end burning SPGG has been introduced.

Mathematical formulation of different burning phases is introduced to get an approximate solution of the relevant differential equations. With this treatment, it is possible to examine the pressure time history including the phases of ignition, burning and tail-off.

Two software programs have been implemented and applied for the calculation of the pressure-time history corresponding to some given propellant data.

The pressure time curves obtained from fire tests indicate that the gas generator is functioning properly. The ignition takes place without problems, the pressure reflects a stable and quite steady burning, the exhaust gases are clear and steady. The pressure decay is smooth and the required mass flow and burning time are satisfactory.

Checking the validity of the proposed mathematical model and the computational solution is done through the comparison of computational and experimental results. The deviation error of computational and measurement results moves within 3\% for program no: 1 and $4 \%$ for program no: 2. Comparison of computational and experimental results showed reasonable.

The implemented programs are considered as an effective tool for the evaluation of the rocket motor performance.

\section{References}

[1] Alain Davenas , "Solid Rocket Propulsion Technology", Paris 1988.

[2] Barrere, M., 'Rocket Propulsion' Elsevier publishing company, 1960.

[3] D.K. Huzel and David .H. Huang, "Modern Engineering For Design of Liquid-Propellant Rocket Engines", Washington, Dc 20024,ISBN 1-56347-013-6,AIAA, 1992.

[4] Wesam El-hasumi "Theoretical and Experimental Investigation of Solid Propellant Gas Generator" MSc thesis, Military Technical College, cairo, Egypt, 2009.

[5] Sutton, G., 'Rocket Propulsion Elements'. Sixth Edition, John Wiley \&Sons, New York, 1992. 